\title{
EFFECT OF TEMPERATURE AND IONOPHORES ON THE PERMEABILITY OF SYNAPTOSOMES
}

\author{
C. A. M. Carvalho and A. P. Carvalho \\ Center for Cell Biology, Department of Zoology, University of Coimbra, Portugal \\ (Received 29 November 1978. Revised 12 February 1979. Accepted 19 February 1979)
}

\begin{abstract}
Synaptosomes swell rapidly in isosmotic solutions of glycerol or urea, but the swelling in solutions of larger non-electrolytes, such as erythritol, glucose or sucrose is slower. The permeability of synaptosomes to non-electrolytes is temperature dependent, and the low activation energies for the permeation of urea $(13 \mathrm{kcal} / \mathrm{mol})$ and erythritol $(9.5 \mathrm{kcal} / \mathrm{mol})$ indicate that the penetration of nonelectrolytes into the synaptosomes does not imply complete dehydration of the molecules.

The relative permeability of synaptosomes to cations, as measured by the rate of swelling in isosmotic solutions of acetate salts is in the order: $\mathrm{NH}_{4}^{+}>\mathrm{Na}^{+}>\mathrm{Li}^{+}>\mathrm{K}^{+}>\mathrm{Ca}^{2+}$. The ionophores, X-537A and nigericin. or valinomycin + FCCP, which promote exchange of cations for $\mathrm{H}^{+}$, cause swelling of synaptosomes in solutions of potassium salts of acetate or propionate, but not in $\mathrm{KCl}$, whereas $\mathrm{H}^{+}$release is higher in $\mathrm{KCl}$ medium. This suggests that the organic anions cross the membrane after combining with $\mathrm{H}^{+}$to form the respective weak acids. The relative permeability to anions is in the order: acetate $\simeq$ propionate $>\mathrm{Cl}^{-}>\mathrm{SO}_{4}^{2-} \simeq$ maleate $\simeq$ succinate.

The energies of activation for the permeability of synaptosomes to potassium acetate in the presence of $\mathrm{X}-537 \mathrm{~A}$ or gramicidin $\mathrm{D}$ are $13 \mathrm{kcal} / \mathrm{mol}$ and $7.5 \mathrm{kcal} / \mathrm{mol}$, respectively, which reflects different mechanisms of action for the two ionophores in the membranes.
\end{abstract}

SYNAPTOSOMES have been used for a wide range of neurochemical studies, especially in experimental approaches designed to study transport and release of neurotransmitters at nerve endings (RAITERI \& Levi, 1978: Kuhar, 1973; Cotman et al., 1976; Olsen et al., 1977; Cahill \& MEdzihradsKy, 1976; Holz, 1975; BRADFORI), 1970, 1975). More recently, the role of ions in these phenomena has been recognized, and synaptosomes have again been the preferred biological system to study the mechanism of action of $\mathrm{Ca}^{2+}$, $\mathrm{Na}^{+}, \mathrm{Li}^{+}$and many other cations (DE BELLEROCHE \& BRADFORD, 1972; OSBORNE et al., 1973; OsBORNE \& BRAdFord, 1975; Blaustein, 1974, 1975; BlausTEIN \& OboRn, 1975; Blaustein \& ECTOR, 1976; STEFANini et al., 1976). Furthermore, it now appears that synaptosomes can also be used to study the intracellular cationic regulation at nerve terminals. Thus, recent studies have been reported on the role of $\mathrm{Na}^{+}$and other cations on the regulation of intracellular $\mathrm{Ca}^{2}{ }^{+}$in nerve using synaptosomes as the experimental biological system (BLAUSTEIN \& ECTOR, 1976; SteFanini et al., 1976; Silbergeld, 1977; ICHIDA et al., 1976), and $\mathrm{Ca}^{2+}$-ATPase and $\mathrm{Ca}^{2+}$ transport systems found in synaptic membranes have also been implicated in $\mathrm{Ca}^{2+}$ regulation by nerve cells (DUNCAN, 1976; RahamimofF \& ABRAMOVITZ, 1978; BLALSTEIN et al., 1978; GodDARD \& RoBInSON, 1976; VICKERS \& DOWDALL, 1976).

Abbreviations used: FCCP, p-trifluorometoxycarbonylcyanide phenylhydrazone; HEPES, N-2-hydroxyethylpiperazone-N'-2-ethanesulfonic acid.
In spite of this wide utilization of synaptosomes to study nerve membrane phenomena, it is surprising that little information exists about the passive permeability properties of synaptosomal membranes (KEeN \& WhITE, 1970, 1971; MARCHBANKS, 1967). Thus, the osmotic response of synaptosomes to various solutions, which can be utilized as an index of simple permeability to ions and non-electrolytes, has not been studied to the same extent as for other isolated vesicular fractions of secretory systems, such as chromaffin granules (PERLMAN, 1976; JOHNSON \& SCarpa, 1976; Phillips, 1977). The osmotic response of these vesicular fractions can be followed by a simple light scattering technique which has been successfully applied in various membrane vesicle systems such as liposomes (BLoK et al., 1976; DE GiER et al., 1968; Antunes-Madeira \& Madeira, 1979; MCELHANEY et al., 1973; DE GIER et al., 1971), mitochondria (Mitchell \& Moyle, 1969; Brierley et al., 1977), chromaffin granules (JOHNSON \& SCARPA, 1976; Phillips, 1977; Phillips \& Allison, 1978; CASEy et al., 1976), sarcoplasmic reticulum (KomETani \& KASAI, 1978) and, to some extent, synaptosomes (KeEN \& White, 1970, 1971; MarchBanKs, 1967).

We present here the results of experiments in which we studied the effect of temperature on the passive permeability of synaptosome fractions isolated from sheep brain cortex to various electrolytes and nonelectrolytes. Furthermore, by utilizing selective ionophores and measuring the $\mathrm{H}^{+}$fluxes coupled to the fluxes of other cations, we were able to measure the net proton production during ionic fluxes. 


\section{MATERIALS AND METHODS}

Preparation of synaptosomes. Synaptosomes were isolated from sheep brain cortex according to the method described by Hajós (1975), with some modifications. Brain cortex $(50 \mathrm{~g})$ was homogenized in 9 vol of $0.3 \mathrm{M}$-sucrose by using a Potter-Elvehjem homogenizer. The homogenate was centrifuged at $1500 \mathrm{~g}$ for $10 \mathrm{~min}$ and the resulting supernatants were centrifuged at $9000 \mathrm{~g}$ for $20 \mathrm{~min}$. The pellets were combined and dispersed in $50 \mathrm{ml}$ of $0.3 \mathrm{M}$-sucrose. Samples of $8 \mathrm{ml}$ of this suspension were carefully layered into each of six tubes containing $30 \mathrm{ml}$ of $0.8 \mathrm{M}$-sucrose and were centrifuged at $9000 \mathrm{~g}$ for $30 \mathrm{~min}$ in an International B- 20 refrigerated centrifuge with an $8 \times 45 \mathrm{ml} \mathrm{fix-}$ ed-angle rotor. The particle fraction dispersed in the $0.8 \mathrm{M}$-sucrose solution (synaptosomal fraction) was collected and adjusted gradually with cold distilled water to $0.4 \mathrm{M}$-sucrose. This suspension of synaptosomes was centrifuged at $20,000 \mathrm{~g}$ for $30 \mathrm{~min}$, and the pellet was washed and suspended in $0.31 \mathrm{M}$-sucrose buffered with $20 \mathrm{~mm}-$ HEPES Tris ( $\mathrm{pH} 7.2$ ) at a protein concentration of $20 \mathrm{mg} / \mathrm{ml}$ as determined by the biuret method described by LAYNE (1957).

We preferred this method of fractionation to the classical method of Gray \& WhitTaker (1962) because the present method compares favorably with the latter in terms of purity of the synaptosomal fraction (Hasós, 1975). In our hands the two methods gave synaptosomal preparations which behaved similarly with respect to their osmotic response.

Permeability of synaptosomes as measured by swelling. Experiments were performed in a thermostated cuvette of a Bausch \& Lomb Spectronic 20 connected to a Vitatron recorder. The turbidity of the synaptosomal suspensions was measured at $440 \mathrm{~nm}$, and continuous stirring of the suspensions permitted recording of the instantaneous changes in turbidity which occurred upon the addition of various substances to the medium.

Permeability to non-electrolytes was determined by following the initial swelling rates of synaptosomes when placed in 0.33 osm solutions of various permeants (urea, glycerol, erythritol, glucose or sucrose), buffered with

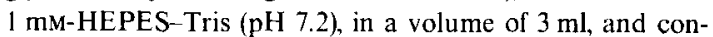
taining a final protein concentration of $0.16 \mathrm{mg} / \mathrm{ml}$. The results of a typical experiment are shown in Fig. 1. The slopes of the tangents at the initial part of the curves (dashed line) are taken as the initial swelling rates of synaptosomes, which are assumed to be proportional to the permeability constant for the permeants (DE GIER et al., 1968).

Permeability to electrolytes was measured in isosmotic solutions $(0.33$ osM) of various salts containing $1 \mathrm{~mm}$ HEPES neutralized with Tris base to pH 7.2 and $0.167 \mathrm{mg} / \mathrm{ml}$ of synaptosomal protein. The various ionophores were prepared in absolute ethanol and the volumes added never exceeded $10 \mu \mathrm{l}$. This volume of absolute ethanol had no effect on the parameters measured.

Production of $\mathrm{H}^{+}$and $\mathrm{Ca}^{2+}$ uptake. The production of $\mathrm{H}^{+}$by synaptosomes was measured in experiments conducted under conditions identical to those used for measuring the swelling, except that higher protein concentrations were utilized $(0.33 \mathrm{mg} / \mathrm{ml})$. The production of $\mathrm{H}^{+}$ was followed continuously using a radiometer combined electrode, type GK $2321 \mathrm{C}$, connected to a radiometer $\mathrm{pH}$ meter, Model PHM 64, and a Perkin-Elmer recorder, Model 56. The system was calibrated at the end of each experiment with freshly titrated $\mathrm{NaOH}$.

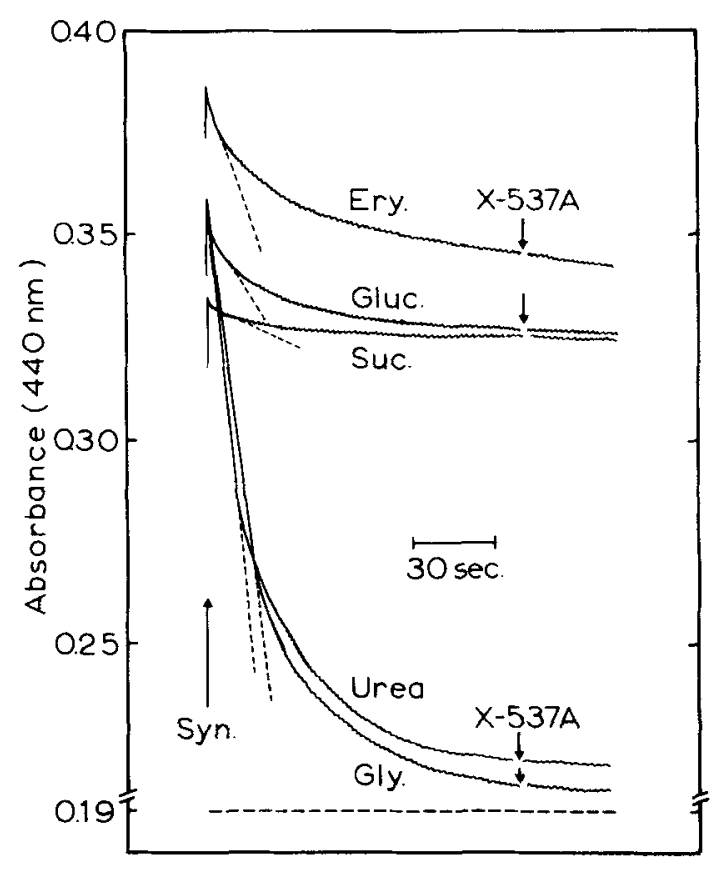

FIG. 1. Swelling of synaptosomes in solutions of non-electrolytes. Synaptosome preparations $(0.133 \mathrm{mg} / \mathrm{ml})$ were incubated in isosmotic solutions ( $0.33 \mathrm{osm})$ of erythritol (Ery.), glucose (Gluc.), urea and glycerol (Gly.) buffered with $1 \mathrm{~mm}$-HEPES-Tris at $\mathrm{pH}$ 7.2. The swelling was followed at $25^{\circ} \mathrm{C}$ by the decrease in absorbance of the suspension measured at $440 \mathrm{~nm}$. Additions of $16 \mu \mathrm{M}-\mathrm{X}-537 \mathrm{~A}$ are indicated by the arrows. The dashed line at the bottom of the figure shows the absorbance of a synaptosomal suspension ruptured in water.

Analyses of $\mathrm{Ca}^{2+}$ were performed by atomic absorption spectrophotometry after filtration of the membrane suspensions through 'Millipore' filters, as described previously (Carvalho \& Carvalho, 1977).

Reagents. The ionophore X-537A was supplied by Dr. Julius Berger, Hoffman-La Roche Inc., Nutley, NJ 07110 , U.S.A. and A23187 was supplied by Dr. RoBert L. Hamill, The Lilly Research Laboratories, Eli Lilly and Company, Indianapolis, IN 46206, U.S.A. Gramicidin D was obtained from Sigma. All other reagents were of analytical grade.

\section{RESULTS}

\section{Permeability of synaptosomes to non-electrolytes}

Preliminary experiments performed in our laboratory showed that synaptosomes behave as ideal osmometers when placed in $\mathrm{KCl}$ solutions whose concentrations are in the range of $100-500$ mosm. Similar observations have been reported previously for synaptosomes (KEEN \& WHITE, 1970) and for liposomes (BAngham et al., 1967). Thus, the permeability characteristics of the synaptosomal membranes can be followed by measuring the osmotic swelling of a synaptosomal suspension in isosmotic solutions ( 330 mosm) of the various permeants. 


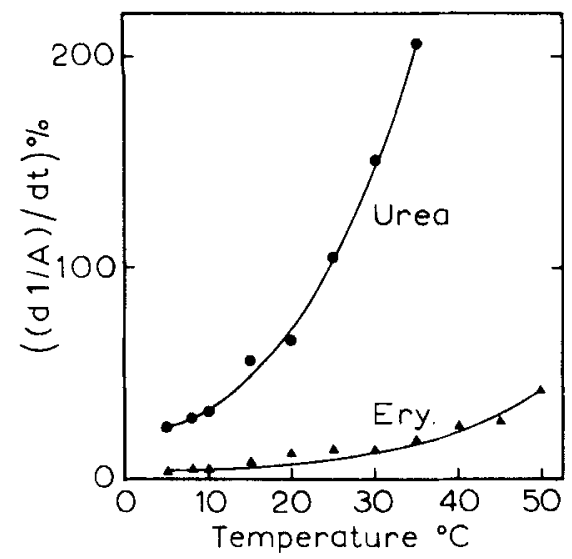

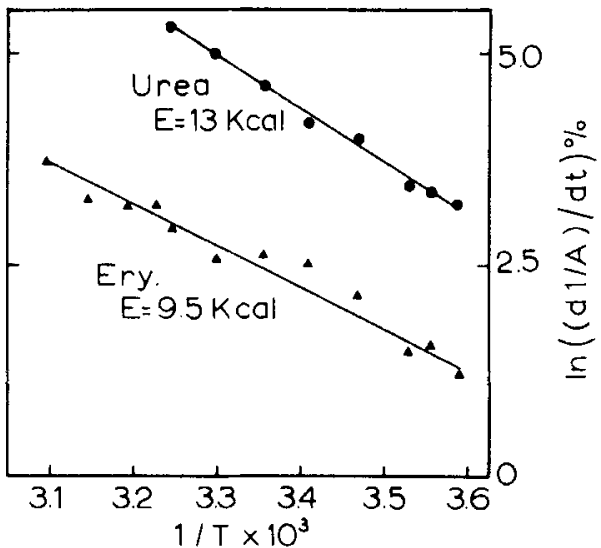

FIG. 2. Temperature dependence of the permeability of synaptosomes to urea and erythritol. A. Initial swelling rates of synaptosomes in isosmotic solutions of urea and erythritol. Other experimental conditions are as described in Fig. 1. B. Arrhenius plots of the data shown in part A and the calculated activitation energies for the permeation of urea and erythritol.

The results shown in Fig. 2 represent the temperature dependence of the permeability of synaptosomes to the non-electrolytes urea and erythritol. The results in Fig. 2A show the swelling rates of synaptosomes calculated as $\mathrm{d}(1 / A) / \mathrm{d} t$ (DE GIER et al., 1971) as a function of temperature. It is observed that in the range of temperatures studied, the permeability of synaptosomes to urea is always much higher than the permeability to erythritol, which probably reflects the relatively small molecular size of the urea molecule. Figure 2B shows Arrhenius plots of the data presented in Fig. 2A. The activation energies for the permeation process, calculated from the slope of the lines, are $9.5 \mathrm{kcal} / \mathrm{mol}$ for erythritol and $13.0 \mathrm{kcal} / \mathrm{mol}$ for urea. These values are much lower than those obtained previously for the permeation of non-electrolytes through lipid bilayers (DE GIER et al., 1971) in which the values of the energies of activation calculated were close to those expected for the complete dehydration of the permeants during the permeation process.

\section{Permeability of synaptosomes to cations}

The results shown in Fig. 3 represent the rate of swelling of synaptosomes in isosmotic solutions of acetate salts. A rapid and extensive swelling of synaptosomes occurred in ammonium acetate, as reported previously (KEEN \& WHITE, 1970, 1971). For the other acetate salts, however, there was only a limited swelling of synaptosomes, which reflects significant apparent differences in the permeability of the synaptosomes to the cations, since the anion, acetate, was the same in all cases. Careful comparison of the rates of swelling just before adding X-537A showed that the permeability of the synaptosomes to the different cations was: $\mathrm{NH}_{4}^{+}>\mathrm{Na}^{+}>\mathrm{Li}^{+}>\mathrm{K}^{+}>\mathrm{Ca}^{2+}$. However, when X-537A was added to the medium, there was a rapid swelling of synaptosomes. The effect of $\mathrm{X}-537 \mathrm{~A}$ on the swelling was most prominent in the cases of $\mathrm{K}^{+}$and $\mathrm{Na}^{+}$acetate, which may indicate that this ionophore preferentially exchanges $\mathrm{K}^{+}$or $\mathrm{Na}^{+}$for $\mathrm{H}^{+}$across the synaptosomal membrane. Since the anion was acetate in all cases, any differences in swelling were due to the cation.

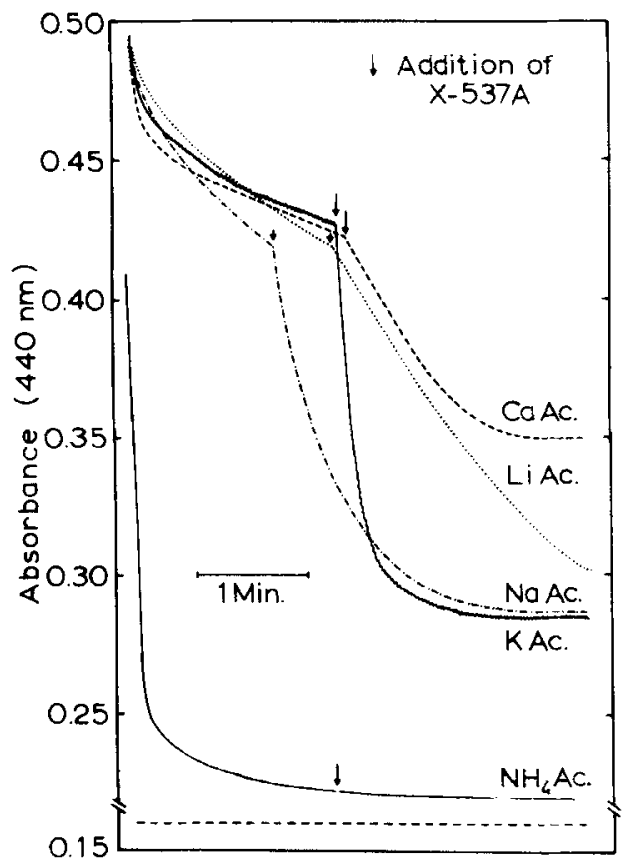

FIG. 3. Swelling of synaptosomes in solutions of various acetate salts. The swelling of synaptosomes, $(0.133 \mathrm{mg} / \mathrm{ml})$ was followed in isosmotic solutions (0.33 osM) of $\mathrm{Ca}^{2+}$, $\mathrm{Li}^{+}, \mathrm{Na}^{+}, \mathrm{Na}^{+}, \mathrm{K}^{+}$and ammonium acetates, buffered with 1 mM-HEPES-Tris at pH 7.2. At the points indicated by the arrows, $16 \mu \mathrm{M}-\mathrm{X}-537 \mathrm{~A}$ was added and the changes in absorbance were followed as in Fig. 1. The dashed line at the bottom of the figure shows the absorbance of a synaptosomal suspension ruptured in water. 


\section{Permeability of synaptosomes to anions}

Figure 4 shows swelling of synaptosomes in potassium salts of various anions. Since the same cation was present in all cases any differences in swelling were due to the anions. Evaluation of the data indicates that the order of permeability of synaptosomes to anions, as indicated by the swelling rates was: acetate $\simeq$ propionate $>\mathrm{Cl}^{-}>\mathrm{SO}_{4}^{2-} \simeq$ maleate $\simeq$ succinate.

When valinomycin is added to a synaptosomal suspension in an isosmotic potassium salt solution, it is the anion which will be rate limiting for swelling, since the $\mathrm{K}^{+}$will cross the membrane freely provided that an anion enters or that another cation leaves the synaptosomes in exchange for $\mathrm{K}^{+}$. Since valinomycin alone does not provide an exchange of $\mathrm{K}^{+}$ for other cations (PrEssman, 1976; Gómez-Puyou \& Gómez-LoJERo, 1977), it is concluded that it is the anion which is rate limiting. However, if FCCP ( $p$-trifluorometoxycarbonylcyanide phenylhydrazone) or an ionophore which promotes a $\mathrm{K}^{+} \leftrightharpoons \mathrm{H}^{+}$exchange, such as nigericin or X-537A, was added we observed that swelling occurred, but only in the presence of some anions (Fig. 4). The $\mathrm{K}^{+} \leftrightharpoons \mathrm{H}^{+}$exchange alone was not a sufficient condition for swelling, since it did not cause alteration of the osmotic pressure. Apparently the $\mathrm{H}^{+}$which left the synaptosomes neutralized the charge of some of the anions of weak acids (acetate and propionate) so that the uncharged species penetrated the membranes. However, maleate and succinate did not behave in the same way, since no swelling was observed in salts of these anions even in the presence of ionophores which promote the $\mathrm{K}^{+} \leftrightharpoons \mathrm{H}^{+}$exchange (Fig. 4). It is possible that these molecules are too large, or that the $\mathrm{H}^{+}$affinity of some of the charged groups of maleate and succinate is too low, so that not all the charges in these molecules were neutralized.

\section{Relationship between $\mathrm{H}^{+}$efflux and swelling produced by ionophores}

The results shown in Fig. 5 further extended these studies to clarify the relation between $\mathrm{H}^{+}$efflux and the swelling caused by the ionophores. As was already observed in Figs. 3 and 4 the ionophore X-537A, which catalyses the electroneutral $\mathrm{K}^{+} \leftrightharpoons \mathrm{H}^{+}$ exchange, produced immediate and extensive swelling of synaptosomes in $\mathbf{K}$ acetate medium, but this effect was only slight in $\mathrm{KCl}$ medium, as shown in Fig. 5A. In order to clarify these observations, the release of $\mathrm{H}^{+}$by synaptosomes was followed in both media, and the results reported in Fig. 5B show that addition of $\mathrm{X}-537 \mathrm{~A}$ to synaptosomes in $\mathrm{K}$ acetate medium induced the release of a smaller amount of $\mathrm{H}^{+}(38 \mathrm{nmol}$ $\mathrm{H}^{+} / \mathrm{mg}$ of protein) than it did in $\mathrm{KCl}$ medium, which caused a release of $53 \mathrm{nmol} \mathrm{H} \mathrm{H}^{+} / \mathrm{mg}$ of protein. One probable explanation is that the same amount of $\mathrm{H}^{+}$ was produced in both cases, but in acetate medium part of the $\mathrm{H}^{+}$was buffered by the acetate anions to form acetic acid and therefore less $\mathrm{H}^{+}$was detected in this case.

The results presented in Fig. $5 \mathrm{C}$ and SD represent

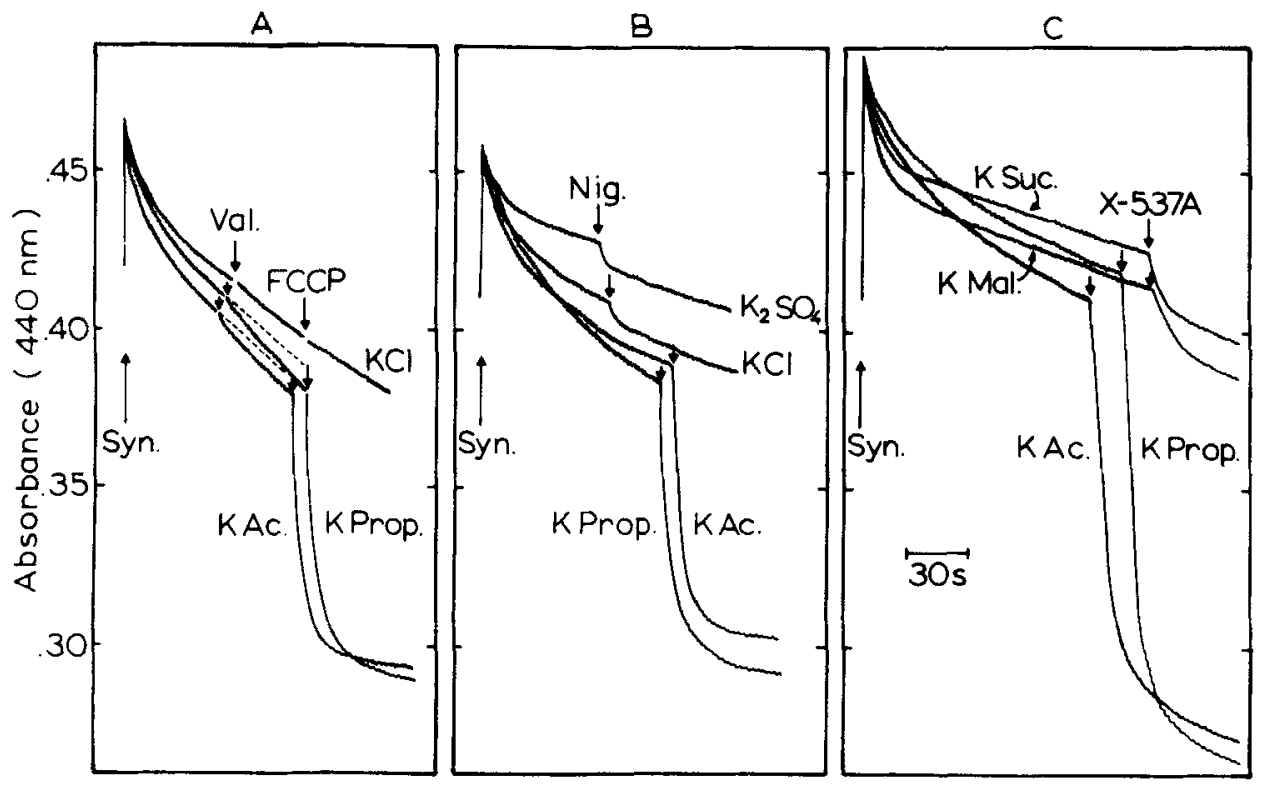

FIG. 4. Effect of ionophores on the swelling of synaptosomes in potassium salts of various anions. Synaptosomes $\left(0.4 \mathrm{mg}\right.$ of protein) were added to $3 \mathrm{ml}$ of 0.33 osm solutions of $\mathrm{K}^{+}$salts of various anions containing $1.0 \mathrm{~mm}$-HEPES-Tris at $\mathrm{pH} 7.2$, at $25^{\circ} \mathrm{C}$. At the times indicated by the arrows the ionophores were added to the medium: A, Valinomycin (Val.), $8.3 \mu \mathrm{g} / \mathrm{ml}$ and FCCP, $0.83 \mu \mathrm{g} / \mathrm{ml}$; B, nigericin (Nig.), $3 \mu \mathrm{g} / \mathrm{ml}$; C, X-537A, $16 \mu \mathrm{M}$. Other abbreviations utilized are; Ac., acetate; Prop., propionate; Mal., maleate; suc., succinate. 


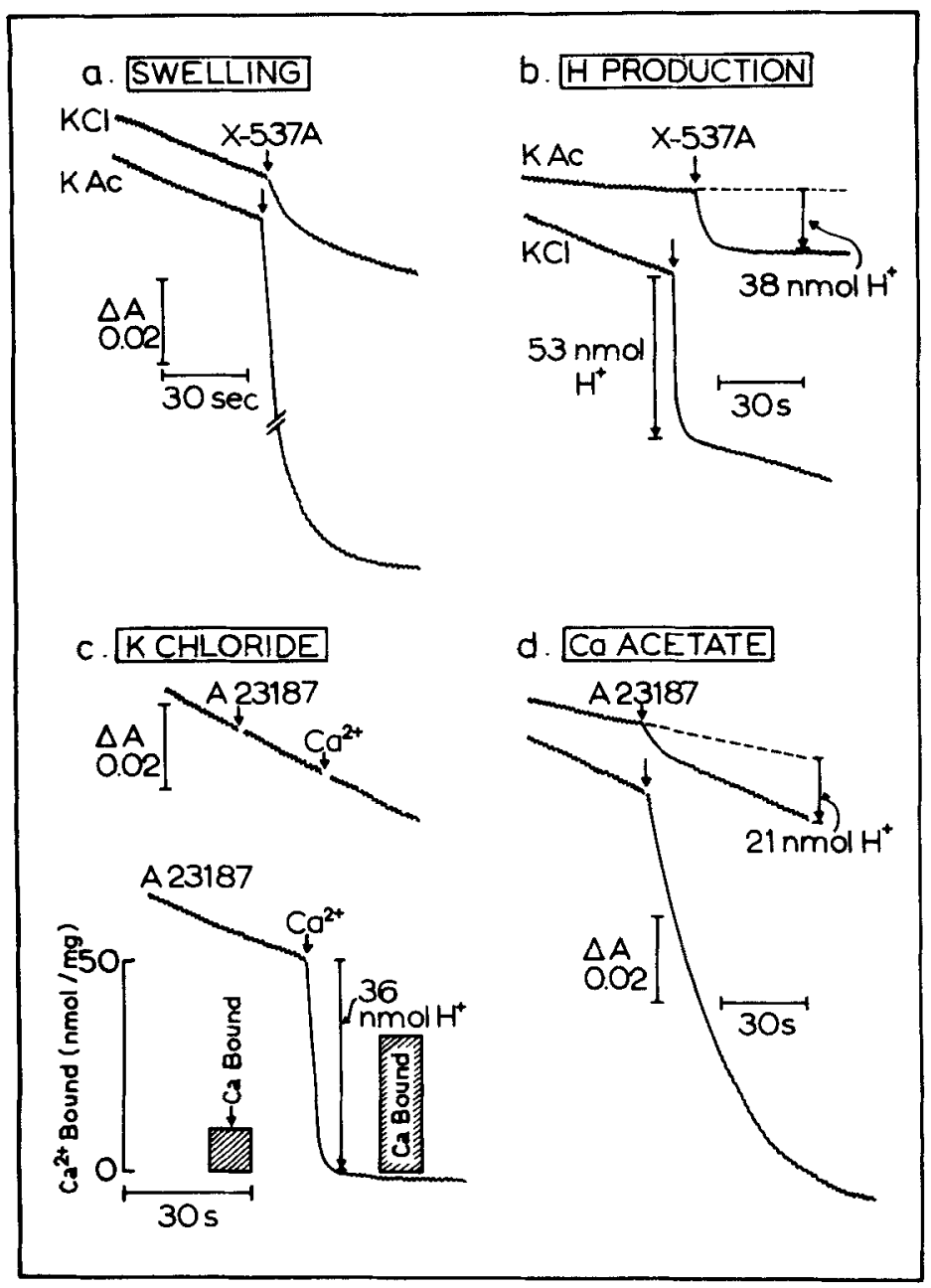

FIG. 5. Effect of ionophores on the permeability of synaptosomes. Effect of X-537A $(16 \mu \mathrm{M})$ on the swelling (A) and $\mathrm{H}^{+}$production (B) by synaptosomes measured in 0.33 osm solutions of $\mathrm{KCl}$ or $\mathrm{K}$ acetate. Effect of $\mathrm{A} 23187$ on the swelling. $\mathrm{H}^{+}$production and $\mathrm{Ca}^{2+}$ uptake (shaded bars) by synaptosomes measured in 0.33 osm solutions of $\mathrm{KCl}(\mathrm{C})$ or $\mathrm{Ca}$ acetate (D). The media were buffered with $1 \mathrm{~mm}$-HEPES-Tris at $\mathrm{pH}$ 7.2. Additions to the media were: $16 \mu \mathrm{M}-\mathrm{X}-537 \mathrm{~A}$ or $\mathrm{A} 23187$ and $0.2 \mathrm{mM}-\mathrm{CaCl}_{2}$, final concentration. Protein concentrations were $0.167 \mathrm{mg} / \mathrm{ml}$ in the swelling experiments and $0.33 \mathrm{mg} / \mathrm{ml}$ in the $\mathrm{H}^{+}$production or $\mathrm{Ca}^{2+}$ uptake experiments.

the effect of A23187 on the permeability of synaptosomes to $\mathrm{Ca}^{2+}$. It was observed that A23187 did not induce swelling of synaptosomes in $\mathrm{KCl}$ medium (Fig. 5C) even though $0.2 \mathrm{~mm}-\mathrm{CaCl}_{2}$ was subsequently added to the medium, but $\mathrm{A} 23187$ produced extensive swelling of synaptosomes in an isosmotic solution (0.33 osm) of $\mathrm{Ca}$ acetate (Fig. 5D). It was also observed that in $\mathrm{KCl}$ medium (Fig. 5C), although the addition of A23187 does not induce swelling of synaptosomes, there was a net $\mathrm{Ca}^{2+}$ uptake of $22 \mathrm{nmol} \mathrm{Ca}^{2+} / \mathrm{mg}$ protein when $0.2 \mathrm{~mm}-\mathrm{Ca}^{2+}$ was added to the medium, and a parallel release of $36 \mathrm{nmol}$ of $\mathrm{H}^{+} / \mathrm{mg}$ of protein, which gives a ratio of exchange of about $1 \mathrm{Ca}^{2+}: 1.6 \mathrm{H}^{+}$, a value which is somewhat lower than the theoretical value of $1 \mathrm{Ca}^{2+}: 2 \mathrm{H}^{+}$. On the other hand, the swelling of synaptosomes in $\mathrm{Ca}$ acetate medium was accompanied by a production of $\mathrm{H}^{+}$of about $21 \mathrm{nmol} / \mathrm{mg}$ of protein (Fig. 5D), which is lower than the production of $\mathrm{H}^{+}$which occurred in $\mathrm{KCl}$ medium.

Influence of temperature on the swelling of synaptosomes induced by $X-537 A$ and gramicidin $D$ in potassium acetate medium

Figure 6 shows representative traces of the results of experiments in which the permeability of synaptosomes to $\mathrm{K}$ acetate was studied at various temperatures. The effects of gramicidin D and X-537A additions on the swelling rates are also shown. It was found that the rate of swelling of synaptosomes was temperature dependent and that the temperature effect also was very prominent upon addition of ionophores, especially X-537A, which indicates that the mobility of this ionophore through the membrane is facilitated by temperature. 


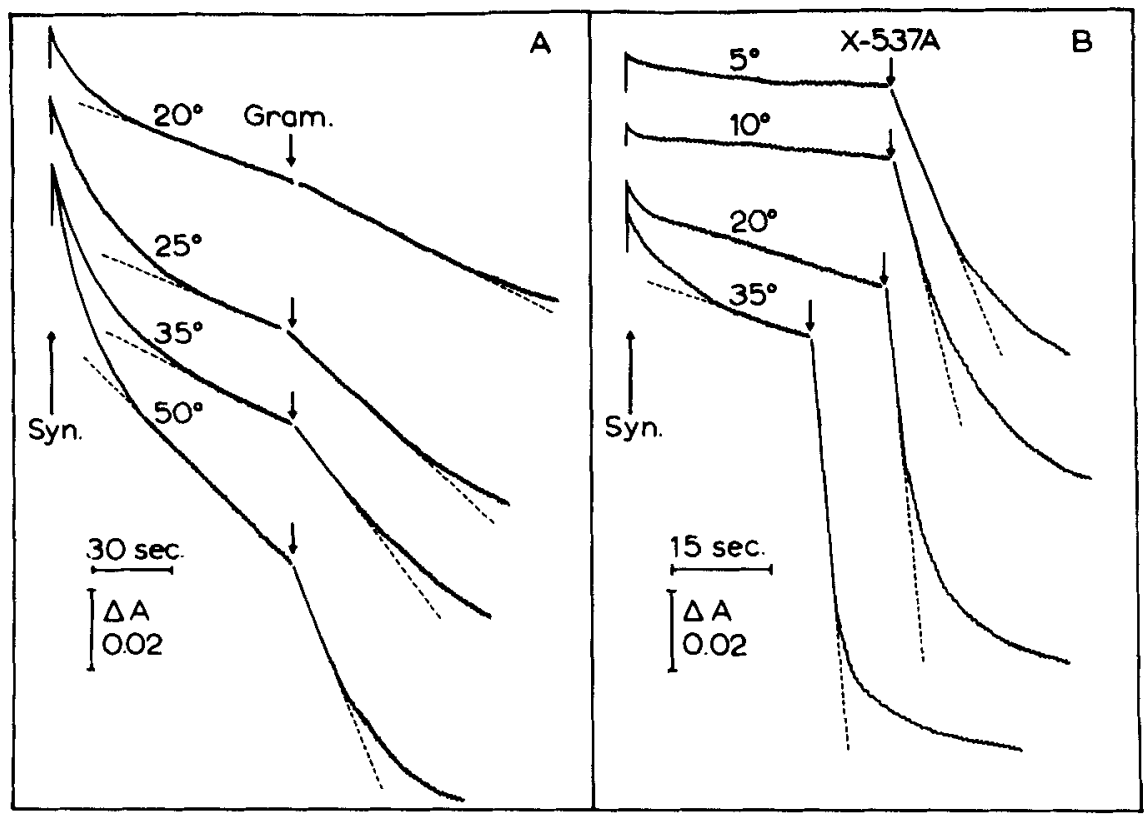

Fig. 6. Effect of temperature on the swelling of synaptosomes in potassium acetate. Synaptosomes $(0.133 \mathrm{mg} / \mathrm{ml})$ were suspended in $0.33 \mathrm{osm}$ solutions of $\mathrm{K}$ acetate buffered with $1 \mathrm{~mm}$-HEPES-Tris at $\mathrm{pH} 7.2$, at the temperatures indicated in the traces. After equilibration with the medium, we added $8.3 \mu \mathrm{g} / \mathrm{ml}$ of gramicidin D (A) or $16 \mu \mathrm{M}-\mathrm{X}-537 \mathrm{~A}(\mathrm{~B})$ and measured the changes in absorbance at $440 \mathrm{~nm}$.

The rates of swelling of synaptosomal preparations in $\mathrm{K}$ acetate upon addition of either X-537A or gramicidin $\mathrm{D}$ were determined, and the results are shown in Fig. $7 \mathrm{~A}$ for the temperature range shown in the abcissa. The X-537A induced swelling of synaptosomes is highly temperature dependent in the temperature range of $5-30^{\circ} \mathrm{C}$. For higher temperatures, the rates of swelling are so high that accurate measurements are impossible.

On the other hand, the gramicidin induced swelling of synaptosomes was studied at temperatures of $5-50^{\circ} \mathrm{C}$, and the results show that the rates of swelling were much lower than those observed in the presence of X-537A, and also were much less temperature dependent. Figure $7 \mathrm{~B}$ shows the energies of activation for both processes calculated from the Arrhenius plots of the data in Fig. 7A. The energy of activation for the gramicidin induced swelling $(7.5 \mathrm{kcal} / \mathrm{mol})$ is much lower than the values determined for the X-537A induced swelling $(13 \mathrm{kcal} / \mathrm{mol})$.

A

$B$

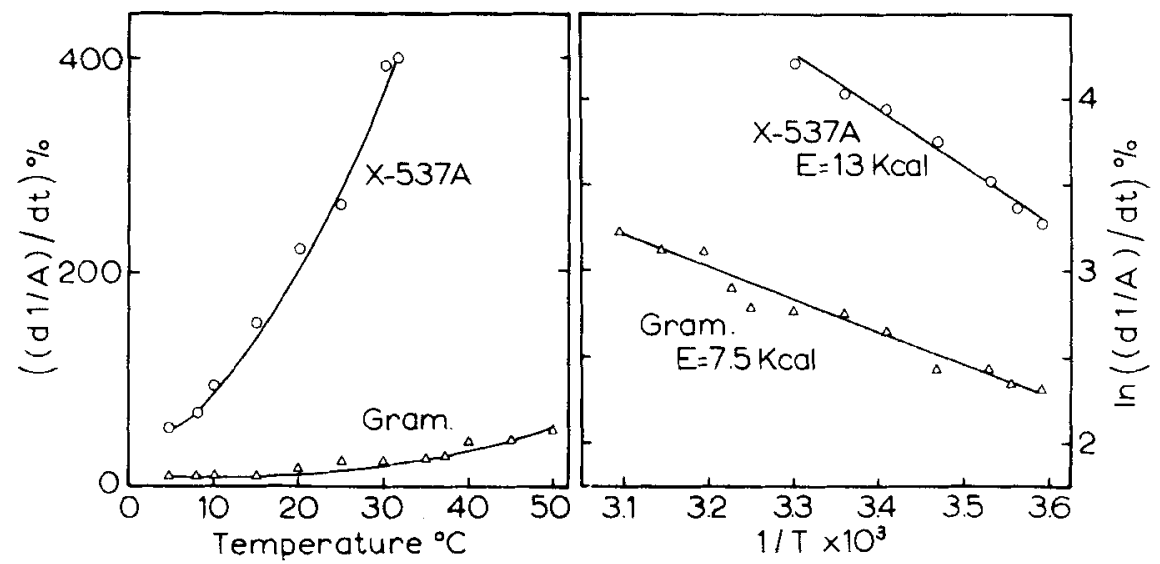

FIG. 7. Temperature dependence of the permeability of synaptosomes to $\mathrm{K}$ acetate induced by $\mathrm{X}-537 \mathrm{~A}$ or gramicidin D. Experimental conditions are those referred to in the legend of Fig. 6. A. Swelling rates of synaptosomes measured in the presence of gramicidin $(8.3 \mu \mathrm{g} / \mathrm{ml})$ or X-537A $(16 \mu \mathrm{M})$, at various temperatures. B. Arrhenius plots of the data shown in part A and calculation of the activation energies for the permeation of $\mathrm{K}$ acetate into synaptosomes in the presence of $\mathrm{X}-537 \mathrm{~A}$ or gramicidin. 


\section{DISCUSSION}

The synaptosomal preparation utilized in this study carries with it a smaller mitochondrial contamination than that of the classical Gray \& WhitTAKer (1962) preparation (HAJós, 1975). Nevertheless, it is important to ascertain that the osmotic effects measured are predominantly those caused in synaptosomes. Previous reports (KeEN \& White, 1970; CaRvalho \& CARVALHO, 1978) show that synaptosomes are relatively impermeable to ammonium phosphate, which permeates the mitochondrial membrane (Mitchell \& Moyle, 1969; Carvalho \& Carvalho, unpublished). Our synaptosomal preparations had only a relatively small osmotic response in isosmotic ammonium phosphate solutions as compared to that of the mitochondrial fraction isolated from the same homogenate, whereas in ammonium acetate solutions synaptosomes showed a slightly higher response than that of mitochondria. Thus, in a preparation composed predominantly of synaptosomes, such as that used in this study, the osmotic response is due mainly to synaptosomes, since the contaminating mitochondria could not account for the large response observed. The microsomal and myelin fractions do not respond osmotically.

Therefore, we believe that within the limitation of our experimental approach, the results reported here provide some understanding of the passive permeability of synaptosomes to non-electrolyte and electrolyte solutes. The results obtained for the permeation of non-electrolytes, such as urea and erythritol (Figs. 1 and 2) into synaptosomes, show that the permeability to urea is higher than the permeability to erythritol. Since both molecules are electrically neutral, the differences in the penetration rates are probably related to the differences in molecular size of the two molecules.

Arrhenius plots for the permeability of synaptosomes to urea and erythritol (Fig. 2B) reveal energies of activation of $13 \mathrm{kcal} / \mathrm{mol}$ for the permeation of urea and $9.5 \mathrm{kcal} / \mathrm{mol}$ for the permeation of erythritol. The value for the energy of activation for erythritol is much lower than that measured for the transfer of this substance across liposomal membranes which are composed exclusively of lipid. For such a system, energy of activation of the order of $20-25 \mathrm{kcal}$ have been reported (DE GIER et al., 1971), which is in agreement with the energies that can be expected if complete dehydration of the erythritol molecule is to occur in its transference from the aqueous phase of the medium into the hydrophobic phase of the lipid membrane. Thus, if we assume that two hydrogen bonds with water are formed per hydroxyl group, eight hydrogen bonds would have to be broken to completely dehydrate erythritol, but the value of five is probably more correct because three intramolecular hydrogen bonds may form in erythritol. Therefore, the enthalpy of dehydration for this molecule should be equivalent to the energy of breaking a maximum of five hydrogen bonds. Since the energy needed to break one hydrogen bond is about $5 \mathrm{kcal} / \mathrm{mol}$, a total of about $25 \mathrm{kcal} / \mathrm{mol}$ would be necessary, whereas we obtain only $9.5 \mathrm{kcal} / \mathrm{mol}$. Thus, in our experiment either erythritol crossed the synaptosomal membrane partially hydrated or another mechanism was responsible for facilitating the transfer of erythritol. The existence of hydrophylic moieties, or pores, in the membrane may permit passage of the molecules without complete dehydration.

The rapid swelling of synaptosomes in $\mathrm{NH}_{4}$ acetate may appear to suggest that the synaptosomal membrane is permeable to both ammonium and acetate ions, but we consider this improbable, since previous experiments (Carvalho \& CaRvalho, 1978) and the results in Fig. 4A show that the membranes are not permeable to acetate in the presence of valinomycin, a carrier for $\mathrm{K}^{+}$. In the case of $\mathrm{NH}_{4}^{+}$the molecule which crosses the membrane was probably $\mathrm{NH}_{3}$ which, as a gas, can permeate easily, and the $\mathrm{H}^{+}$dissociated from $\mathrm{NH}_{4}^{+}$is bound by $\mathrm{CH}_{3} \mathrm{COO}^{-}$to form acetic acid which could then have crossed the membrane as an uncharged molecule. Thus, the end result would be the penetration of ammonium acetate, which would have increased the osmotic pressure inside and caused a net influx of $\mathrm{H}_{2} \mathrm{O}$, which causes swelling. This interpretation is also supported by the fact that synaptosomes did not swell in solutions of ammonium salts of strong acids, such as $\mathrm{NH}_{4} \mathrm{Cl}$ or $\left(\mathrm{NH}_{4}\right)_{2} \mathrm{SO}_{4}$ (CARvalho \& Carvalho, 1978).

The permeability to anions as reflected by the rate of swelling of synaptosomes when they are made permeable to the cation in the medium by ionophores is revealing in that the effects of two types of ionophores could be discerned: valinomycin which allowed $\mathrm{K}^{+}$to cross the membrane and X-537A, A23187 and nigericin which induced the exshange of various cations for $\mathrm{H}^{+}$across the membrane (Pressman, 1976; Gómez-Puyou \& Gómez-Lojero, 1977). The results in the two cases are different (Fig. 4), and the swelling rate is a reflection of the permeability to anions only in the case of the inorganic anions studied $\left(\mathrm{Cl}^{-}\right.$and $\left.\mathrm{SO}_{4}^{2-}\right)$, or in the case in which valinomycin is present. When X-537A (or A23187) was present and the salt in the medium had an organic dissociable anion (acetate, propionate, succionate and maleate), the $\mathrm{H}^{+}$which exchanged for the external cation caused the formation of the corresponding acid which, being neutral, apparently crossed the membrane easily. This conclusion is supported by the fact that valinomycin alone did not cause swelling of synaptosomes in $\mathrm{K}$ acetate or propionate, but swelling readily occurred when FCCP was added in addition to valinomycin (Fig. 4A).

The addition of X-537A to synaptosomes in $\mathrm{K}$ acetate medium caused extensive swelling, but only a limited $\mathrm{H}^{+}$production ( $38 \mathrm{nmol} / \mathrm{mg}$ protein), whereas in $\mathrm{KCl}$ medium there was no swelling, but a higher $\mathrm{H}^{+}$production $(53 \mathrm{nmol} / \mathrm{mg}$ protein). These results are compatible with the idea that part of the $\mathrm{H}^{+}$ 
liberated by the addition of X-537A was buffered by the external acetate to form acetic acid which could permeate the membrane and induce swelling, whereas $\mathrm{Cl}^{-}$did not enter the membrane in the charged form nor could it bind $\mathrm{H}^{+}$. Therefore, in $\mathrm{KCl}$ medium, all $\mathrm{H}^{+}$liberated by $\mathrm{X}-537 \mathrm{~A}$ addition was detected in the medium.

A swelling response was also induced by the specific $\mathrm{Ca}^{2+}$ ionophore $\mathrm{A} 23187$ when it was added to synaptosomes suspended in calcium acetate medium (Fig. 5D). The ratio of $\mathrm{Ca}^{2+} \rightleftharpoons \mathrm{H}^{+}$exchange induced by $\mathrm{A} 23187$ in $\mathrm{KCl}$ medium, upon addition of $0.2 \mathrm{~mm}-\mathrm{CaCl}_{2}$, was $1.0 \mathrm{Ca}^{2+}: 1.6 \mathrm{H}^{+}$. Similar results were previously obtained for chromaffin granules (JOHNSON \& SCARPA, 1976). The amount of $\mathrm{Ca}^{2+}$ which penetrated under these conditions was not sufficient to induce osmotic changes, probably because it was present in a low concentration as compared to the concentration of $\mathrm{KCl}$ of the medium.

In the study of the effect of temperature on the permeability of synaptosomes induced by X-537A and gramicidin D ionophores, we observed that both ionophores increased the permeability to cations. However, X-537A carries the ions $\left(\mathrm{Na}^{+}, \mathrm{K}^{+}, \mathrm{H}^{+}\right.$, $\mathrm{Ca}^{2+}$, etc.) across the membrane, whereas gramicidin $\mathrm{D}$ forms channels which allow the ions to permeate the membrane (PRESSMAN, 1976; BAMBerg \& LÄUGER, 1974,1977 ), and we would expect the two mechanisms for increasing the permeability of the membrane to differ in their responses to temperature. The results obtained show that the energy of activation for the gramicidin D induced swelling $(7.5 \mathrm{kcal} / \mathrm{mol})$ was much lower than the energy of activation of the $\mathrm{X}-537 \mathrm{~A}$ induced swelling $(13 \mathrm{kcal} / \mathrm{mol})$. The high sensitivity to temperature of the $\mathrm{X}-537 \mathrm{~A}$ mechanism is probably correlated with the mobility of the ionophore as a carrier, in the lipid portion of the membrane. On the other hand, the lower sensitivity to temperature of the gramicidin $\mathrm{D}$ induced swelling probably indicates that the gramicidin channels which were formed at the various temperatures were less affected by the temperature than the mobility of the complexes formed between the ions and X-537A.

The synaptosomal membranes behave similarly to other natural membranes in their permeability properties and in their response to ionophores (Gómez-PuYou \& Gómez-LOJERo, 1977). They are relatively impermeable to ions and large neutral molecules and, in situ, the passive permeability to ions of these membranes is altered either by an action potential or by a chemical mediator. The important question which remains to be resolved is how such alteration in permeability occurs and how, in the presynaptic membrane, it leads to secretion of neurotransmitters. We are utilizing synaptosomal preparations to study these phenomena.

Acknowledgements-We thank Professor VITOR M. C. MadeIRA for many interesting discussions and suggestions during the course of this work. This research was sup- ported by I.N.I.C., The Portuguese National Institute for Scientific Research and by NATO Research Grant No. 1513.

\section{REFERENCES}

Antunes-Madeira M. C. \& Madeira V. M. C. (1979) Interaction of insecticides with lipid membranes. Biochim. biophys. Acta 550, 384-392.

Bamberg E. \& LäUger P. (1974) Temperature-dependent properties of gramicidin A channels. Biochim. biophys. Acta 367, 127-133.

BAMBERG E. \& LäUGER P. (1977) Blocking of the gramicidin channel by divalent cations. J. Membrane Biol. 35, 351-375.

Bangham A. D., De Gier J. \& Greville G. D. (1967) Osmotic properties and water permeability of phospholipid liquid crystals. Chem. Phys. Lipids 1, 225-246.

Blaustein M. P. (1974) The interrelationship between sodium and calcium fluxes across cell membranes. Rev. Physiol. Biochem. Pharmac. 70, 33-82.

Blaustein M. P. (1975) Effects of potassium, veratridin and scorpion venom on calcium accumulation and transmitter release by nerve terminals in vitro. J. Physiol., Lond. 247, 617-655.

Blaustein M. P. \& ECtor A. C. (1976) Carrier-mediated sodium-dependent and calcium-dependent calcium efflux from pinched-off presynaptic nerve terminals (synaptosomes) in vitro. Biochim. biophys. Acta 419, 295-308.

Blaustein M. P. \& Oborn C. J. (1975) The influence of sodium on calcium fluxes in pinched-off nerve terminals in vitro. J. Physiol, Lond. 247, 657-686.

Blaustein M. P., Ratzalaff R. W. \& Kendrick N. K. (1978) The regulation of intracellular calcium in presynaptic nerve terminals. Ann. N.Y. Acad. Sci. 307, 195-211.

Blok M. C., Van Deenen L. L. M. \& De Gier J. (1976) Effects of the gel to liquid crystalline phase transition on the osmotic behaviour of phosphatidylcholine liposomes. Biochim. biophys. Acta 433, 1-12.

BradFord H. F. (1970) Metabolic response of synaptosomes to electrical stimulation: release of amino acids. Brain Res. 19, 239-247.

BRADFORD H. F. (1975) Isolated nerve terminals as an in vitro preparation for the study of dynamic aspects of transmitter metabolism and release, in Handbook of Psychopharmacology (IVERSEN L. L., IVERSEN S. D. \& SNYDER S. H., eds) Vol. 1, pp. 191-252. Plenum Press, New York.

Brierley G. P., Jurkowitz M., Chávez E. \& JunG D. W. (1977) Energy-dependent contraction of swollen heart mitochondria. J. biol. Chem. 252, 7932-7939.

Cahill A. L. \& Medzihradsky F. (1976) Interaction of central nervous system drugs with synaptosomal transport process. Biochem. Pharmac. 25, 2257-2264.

Carvalho C. A. M. \& Carvalho A. P. (1977) Fluorimetric monitoring of calcium binding to sarcoplasmic reticulum membranes. Biochim. biophys. Acta 468, 21-30.

Carvalho C. A. M. \& Carvalho A. P. (1978) Passive permeability of synaptosomes studied in the presence of various ionophores. Ciênc. Biol., Portugal 3, 23-40.

Casey R. P., Nuus D., Radda G. K. \& Sehr P. A. (1976) Adenosine triphosphate-evoked catecholamine release in chromaffin granules. Biochem. J. 158, 583-588.

Cotman C. W., Haycock J. W. \& White W. F. (1976) Stimulus-secretion coupling processes in brain: analysis 
of noradrenaline and gamma-aminobutyric acid release. J. Physiol, Lond. 254, 475-505.

De Belleroche J. S. \& Bradford H. F. (1972) The stimulus-induced release of acetylcholine from synaptosome beds and its calcium dependence. J. Neurochem. 19, 1817-1819.

De Gier J. Manderscoot J. G. \& van Deenen L. L. M. (1968) Lipid composition and permeability of liposomes. Biochim. biophys. Acta 150, 666-675.

De Gier J., Mandersloot J. G., Hupkes J. V., McElHANEY R. N. \& VAN BeEK W. P. (1971) On the mechanism of non-electrolyte permeation through lipid bilayers and through biomembranes. Biochim. biophys. Acta 233 , $610-618$.

Duncan C. J. (1976) Properties of the $\mathrm{Ca}^{2+}$-ATPase activity of mammalian synaptic membrane preparations. J. Neurochem. 27, 1277-1279.

Goddard G. A. \& Robinson J. D. (1976) Uptake and release of calcium by rat brain synaptosomes. Brain Res. 110, $331-350$.

Gómzz-Puyou A. \& Gómez-Lojero C. (1977) The use of ionophores and channel formers in the study of the function of biological membranes. Curr. Top. Bioenerg. 6, $221-257$.

Gray E. G. \& WhitTaker V. P. (1962) The isolation of nerve endings from brain: an electron microscopic study of cell fragments derived by homogenization and centrifugation. J. Anat. 96, 79-87.

Hajós F. (1975) An improved method for the preparation of synaptosomal fractions in high purity. Brain Res. 93, 485-489.

Holz R. W. (1975) The release of dopamine from synaptosomes from rat striatum by the ionophores X-537A and A-23187. Biochim. biophys. Acta 375, 138-152.

ICHIDa S., Hata F., Matsuda T. \& Yoshida H. (1976) Effects of $\mathrm{Na}^{+}$and other monovalent cations on $\mathrm{Ca}$ efflux from synaptosomes. Jap. J. Pharmac. 26, 31-37.

JOHNSON R. G. \& SCARPA A. (1976) Ion permeability of isolated chromaffin granules. J. gen. Physiol. 68 , 601-631.

Kfen P. \& White T. D. (1970) A light-scattering technique for the study of the permeability of rat brain synaptosomes in vitro. J. Neurochem. 17, 565-571.

KEEN P. \& White T. D. (1971) The permeability of pinched-off nerve endings to sodium, potassium and chloride and the effects of gramicidin. J. Neurochem. 18, 1097-1103.

Kometani T. \& KaSaI M. (1978) Ionic permeability of sarcoplasmic reticulum vesicles measured by light scattering method. J. Membrane Biol. 41, 295-308.

KUHAR M. L. (1973) Neurotransmitter uptake: a tool in identifying neurotransmitter-specific pathways. Life Sci. $13,1623-1634$.
LAYNE E. (1957) Spectrophotometric and turbidimetric method for measuring proteins, in Methods in Enzymology (Colowick S. P. \& Kaplan N. O., eds.) Vol. 3, pp. 447-451. Academic Press, New York.

Marchbanks R. M. (1967) The osmotically sensitive potassium and sodium compartments of synaptosomes. Biochem. J. 104, 148-157.

McElhaney R. N., De Gier J. \& Van der Neut-Kok E. C. M. (1973) The effect of alterations in fatty acid composition and cholesterol content on the non-electrolyte permeability of Acholeplasma laidlawii B cells and derived liposomes. Biochim. biophys. Acta 298, 500-512.

Mitchell P. \& Moyle J. (1969) Translocation of some anions cations and acids in rat liver mitochondria. Eur. J. Biochem. 9, 149-155.

Olsen R. W. Lamar E. E. \& Bayless J. D. (1977) Calcium-induced release of $\gamma$-aminobutyric acid from synaptosomes: effects of tranquilizer drugs. J. Neurochem. 28, 299-305.

OsBorne R. H. \& BRAdFoRd H. F. (1975) The influence of sodium, potassium and lanthanum on amino acid release from spinal-medullary synaptosomes. $J$. Neurochem. 25, 35-41.

Osborne R. H., Bradford H. F. \& Jones D. G. (1973) Patterns of amino acid release from nerve-endings isolated from spinal cord and medulla. J. Neurochem. 21, 407-419.

Perlman R. L. (1976) The permeability of chromaffin granules to non-electrolytes. Biochem. Pharmac. 25, 1035-1038.

Phillups J. H. (1977) Passive ion permeability of the chromaffin-granule membrane. Biochem. J. 168, 289-297.

Phillips J. H. \& Allison Y. P. (1978) Proton translocation by the bovine chromaffin-granule membrane. Biochem. J. 170, 661-672.

Prissman B. C. (1976) Biological applications of ionophores. A. Rev. Biochem. 45, 501-530.

Rahamimoff H. \& Abramovitz E. (1978) Calcium transport in a vesicular membrane preparation from rat brain synaptosomes: FEBS Lett. 89, 223-226.

RaIteri M. \& Levi G. (1978) Release mechanisms for catecholamines and serotonin in synaptosomes. Rev. Neurosci. 3, 77-130.

Silbergeld E. K. (1977) $\mathrm{Na}^{+}$regulates release of $\mathrm{Ca}^{2+}$ sequestered in synaptosomal mitochondria. Biochem. biophys. Res. Commun. 77, 464-469.

Stefanini E., Argiolas A. \& Gessa G. L. (1976) Effect of lithium on dopamine uptake by brain synaptosomes. J. Neurochem. 27, 1237-1239.

Vickers G. R. \& Dowdall M. J. (1976) Calcium uptake in preterminal central synapses: importance of mitochondria. Expl. Brain Res. 25, 429-445. 